Proceedings of the C.E.R.N. Symposium on High Energy Accelerators and Pion Physics

Geneva, 11th-23rd June, 1956. Vol. 1 : High Energy Accelerators. Pp. xiii +567 . Vol. 2: Pion Physies. Pp. xii +443. (Geneva: C.E.R.N., Service d'Information, 1956.) 40 Swiss franes each volume.

THE 1956 Symposium of the European Organ1 ization for Nuclear Research has already been reported in Nature $(178,116 ; 1956)$. Vol. 1 of the Proceedings deals with high-energy accelerators, and Vol. 2 with some techniques and results of highenergy nuclear research. The early publication of these large volumes, each containing about eighty papers and summaries of the discussion, is a noteworthy achievement, particularly since the standard of production is excellent throughout. Many of the papers contain much more detail than could be covered in the spoken versions, because authors were asked to submit detailed texts before the symposium; these 'preprints' greatly aided discussion, and now, with corrections where necessary, form the basis of the Proceedings. With the inclusion of many papers by Soviet authors, Vol. 1 is the most comprehensive collection of papers on high-energy accelerators which has yet appeared; most of the information was previously either unobtainable or buried in a mass of project reports of many laboratories, and the degree of detail reported in many casses far exceeds what can be accepted nowadays in the journals. Consequently, Vol. I will be most valuable to accelerator specialists. Vol. 2 is not so all-embracing, by design of the organizers; save for an important contribution on anti-proton physics, it is restricted to the lower energy ranges. Moreover, the preparation of lengthy 'preprints' is less readily applicable to nuclear research than to studies of accelerators or techniques. Nevertheless, the same high quality of material and presentation is apparent, and at 40 Swiss francs per volume the Proceedings are a bargain. It is a matter for satisfaction that this highly successful symposium was organized by a young international institute, set up by the cooperative efforts of twelve nations.

T. G. Pickavance

Atomic Structure and the Strength of Metals

An Account for the Nonscientist of Recent Researches aimed at understanding why Metals have their Characteristic Strength and Ductility. By Prof. N. F. Mott. (The Page-Barbour Lectures for 1956 at the University of Virginia.) Pp. vi $+64+13$ plates. (London and New York : Pergamon Press, Ltd., 1956.) 15s. net; 2.75 dollars.

THE accepted way to write a popular book on science is to describe things obviously wonderful: stellar nebulæ, atomic nuclei, living cells, and the like. But this does not properly reflect the scientific attitude--the urge to understand the working of all things, large or small, near or far, domestic or cosmic. In this little book Prof. N. F. Mott has attempted to convey to the non-scientist some feeling for this scientific attitude by arousing his interest in all the intriguing, difficult and surprising questions that have to be faced. when one really tries to explain such a familiar process as the bending and breaking of a piece of metal. Writing with great clarity and simplicity, he first discusses the crystal structures of metals, to understand how atoms are packed together, and then shows that the only way to understand how these atoms slip past each other, or pull apart, is to think of the crystal as a kind of 'space' in which there exists various kinds of 'particles'-dislocations, vacancies, impurity atoms - with properties as intricate and fascinating as those of ordinary space. The understanding of these particles not only leads to the explanation of the strength of metals ; it also enables one to solve a whole range of other problems, from the mechanism of crystal growth to the development of the photographic image.

Anyone who is a scientist at heart could not fail to enjoy this book, irrespective of whether he has been trained in science or not. A. H. Cottrell

Man, Culture, and Society

Edited by Dr. Harry L. Shapiro. Pp. xiii $+380+13$ plates. (London and New York: Oxford University Press, 1956.) 45s. net.

THIS book comprises sixteen chapters by leading experts in anthropology. Most of the authors are American, but three chapters are contributed by British and one by a French scholar. It is a pity that Dr. Shapiro, of the American Museum of Natural History, did not write the whole volume himself or at least that he could not have made do with one or two colleagues : collective works are dull at the best of times and never more so than when written at an elementary level; indeed, some chapters read as though they were written to redeem promises and few can have given their authors much pleasure to compose.

The topics range from the biological endowment of man-dealt with by the editor himself in the opening chapter-to his prehistoric past (Chapters 2-4), the nature and growth of his culture and various aspects of his social life, such as language and writing, religion, economics and social grouping. Of the archæological chapters, Prof. Cressman's on "Man in the New World", describing the prehistory and achievement of the pre-Columban Indians, will probably be read with greatest interest by English readers. Prof. Hoebel contributes a clear statement of the nature of culture, and there are interesting chapters on some of the factors in cultural change. Language and writing, subjects too often neglected by contemporary British anthropologists, are well treated by Prof. Harry Hoijer. Prof. Redfield brings the volume to an end with a trenchant essay on "How Human Society Works". The book might serve for the initial year of undergraduate courses in anthropology.

J. G. D. Clark

\section{A Handbook for the Identification of Insects of} Medical Importance

By Dr. John Smart. With Chapters on Fleas by Dr. Karl Jordan, and on Arachnids by R. J. Whittick. Third edition. Pp. $x i+303+13$ plates. (London: British Museum (Natural History), 1956.) $40 s$.

T $\mathrm{HE}$ third edition of this work was issued in March 1956. It differs little from the second edition of 1948, being a photo-litho reprint of this. Bibliographical references have been brought up to date, however, and some additions and corrections made in the text and in an appendix on mosquitoes. One regrets the increased cost from $£ 1$ in 1948 to $£ 2$ for the third edition. Nevertheless, it still remains a worth-while purchase for those who wish or need within the limits of a single book, well illustrated and bound, and of convenient size, information on the systematics and distribution of arthropods of medical importance.

D. S. Bertram 